\title{
Adapting Social Network to Make Effective Class Room Learning: A Case Study Facebook
}

\author{
Md. Mijanur Rahman ${ }^{1}$, Kazi Imdadul Islam ${ }^{2}$ Tapushe Rubaya Toma ${ }^{3}$ \\ ${ }^{1,2,3}$ Department of Software Engineering, Daffodil International University, Dhanmondi, Dhaka, Bangladesh
}

\begin{abstract}
Social networks are most important part of our daily life. It makes our life easy in the area of entertainment, communication, business, education and etc. Social network, like Facebook is an indefeasible part of life among the social network based people. This place opens an outer world before them where they are comfort to move over it. It is a platform where everybody can access without any hesitation. Most of the user of the Facbook is students and they are spending lot of time in Facebook. Even more number of people login many times in Facebook with their willingness and different purpose. In this context we can use Facbook to make their study interactive and interesting. At the same time, in traditional class-room learning, students become bore to attend the same style teacher's lecture. If we can able to use social network as a supported tool of education, we may make effective our classroom education for young generation in continuous learning process. In this paper, we will try to show the path through which the networking will becomes an educational tool and the students may able to go outsides off their bookies knowledge.
\end{abstract}

Key Words: Social Networks, Facebook, E-learning, Traditional Education System, Facebook group,

\section{Introduction}

In neo years, the continuous change of Internet creates a turbulent in our society and the best benediction of Internet is introducing social networking. It enrolling daily life activities of millions people through enabling information and resource sharing, communication, and collaboration [1]. This is an open environment to interact with others. For that strong position a huge number of people especially our young generation are getting down on it rapidly. They never fill any boarder when they try to know some things. It is extremely dangerous for youth and become enormously common and widespread in past few years joining eagerly in social network like Facebook [2]. For that reason some times they lost their way. At the same time, in ours class room the lecturer comes with a marker and some books. They start to read a topic from the book and try to make the students understand. Sometimes he asks some questions to students or gives homework. At that way some captures the knowledge but maximum not. So they are trying to miss the class and remain backside of life. At that point, engagement between a student and academic is of key importance and social networking may be able to facilitate this engagement [3]. This is a place, where there is no any strong rule, formal way to communicate. So we are going to show a new learning process by using social networking tools. The traditional class is motivated to adopt new style of teaching methodology with the support of networking. This is a place, where we can gather not only current and previous students but also the teachers. With the involvement of teacher and students we may motivate those students who are losing their interest in class. In Facebook there may have a group according to course through which all educational tools will provide by lecturer and all the students will join. They openly discuss there about the topics and collect information as much as they want. This will become an open place for them to visit, what he wants to know and which course is best for him. Through using this networking tools, we might introduce informal but lifelong education by motivate students and increasing their participation. In Figure 1, we show the way through our class room education system can able to adopt the social media and make it a supported part of classroom education.

\begin{tabular}{|c|c|c|}
\hline Instructor tools & & Better Learning \\
\hline$\downarrow$ & & 个 \\
\hline Website & & Increasing challenges \\
\hline Reference Book & $\begin{array}{l}\text { Online discuss } \\
\text { join both }\end{array}$ & Full Participation \\
\hline Online lecture & $\begin{array}{l}\text { 1 eacher \& } \\
\text { Students }\end{array}$ & Self-Paced learning \\
\hline
\end{tabular}

Figure 1: Process of social network learning 


\section{E-learning}

When electronic device is used to spread education around the world without any board is may declare e-learning. E-learning now becomes an open school for all over the world. To improve the quality of learning by increasing facility access of recourses and services of new multimedia technology and internet is now burning question [4]. This is a combination of learning process and technology to provide high value of integrated learning without maintaining time and place [5]. Eliciting learning experiences can also highlight a wide spectrum of individual experiences which would be difficult to predict [6]. Adult and community learning, a sector distinct from further and higher education in role and ethos, occupies a vital role in widening participation, encouraging lifelong learning and in providing all, especially disenfranchised, adults with the skills and access to technology they require as citizens in an information age [7]. It provides many facilities of that student who wants to learn more.

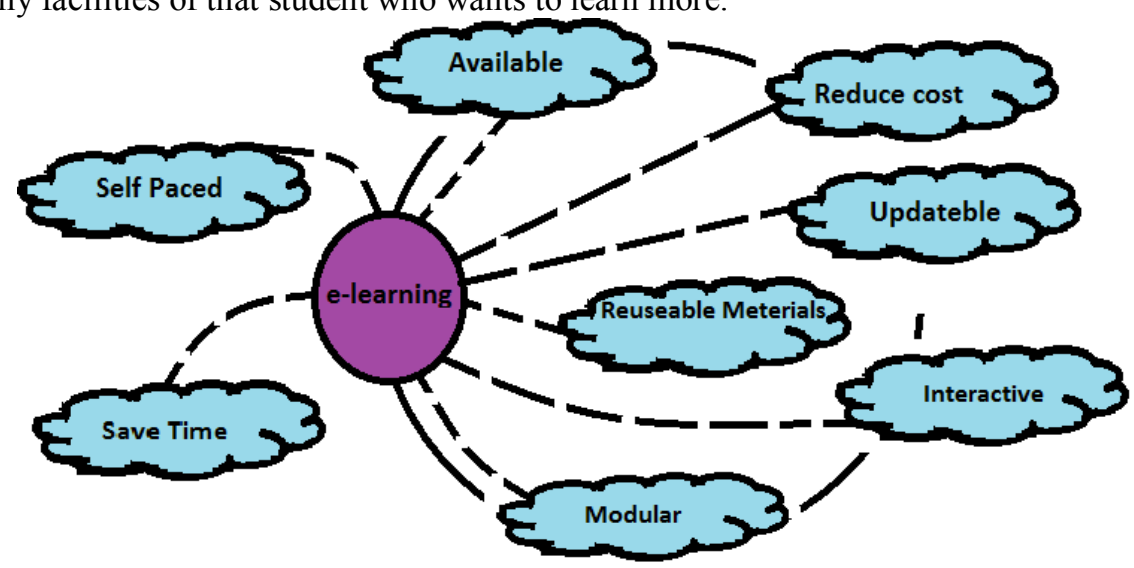

Figure2: Facilities promote by E-learning

Available: The social media is now available to all. Through an internet connection any one can access this and able to get its facilities.

Reduce Cost: By removing distance, it saves money because through e-learning a learner can know about any topics setting at home at any corner of the world.

Updatable: Through this anyone can able to remain up to date with the modern life.

Self-paced: E-learning help to make self-paced. This is only a way where every person may access according to his own wish.

Reusable Materials: Anyone can use it any place any time and a thousand of time.

Interactive: Through social media e-learning becomes interactive to all.

Modular: Anyone can access this any time.

Save Time: With the help of e-learning students can able to save his time.

If we can able to inquire e-learning with our class room education, we will able to modify a huge numbers of students to make them attentive to gather knowledge according to their wish.

\section{Social Networking}

Nowadays social networking becomes most popular and familiar communication tools in our society. It is a way for people to connect and share information with each other online. Millions of people worldwide regularly access these types of services from mobile devices, applications, and websites. Social network provides various shared files, photos and videos, create blogs and send messages, and conduct real-time conversations [5]. Social networks are communicates of people who share common interest and activities in social websites. There is a good number of Social Sites like Facebook, Twitter and MySpace etc. are most common sites.

We define social network sites as web-based services that allow individuals to construct a public or semi-public profile within a bounded system, articulate a list of other users with whom they share a connection, and view and traverse their list of connections and those made by others within the system. The nature and nomenclature of these connections may vary from site to site [8].

According to the Pew Internet \& American Life Project, more than 93\% of both teens [12-17] and young adults (18-29) in the United States use the Internet regularly, and more than $70 \%$ use social networking sites. Furthermore, among online teens, $62 \%$ use the internet to get news about current events and politics, $48 \%$ use it to make purchases (books, clothing, and music), and 31\% use it to get health, dieting, or physical fitness information. 
According to statistics published by some of the most well-known social networking services, there are more than 500 million active users on Facebook ${ }^{1}, 175$ million registered users on Twitter $^{2}$, more than 100 million users on MySpace ${ }^{3}$, and more than 80 million members on LinkedIn ${ }^{4}$

Facebook: the most popular social networking site; use in world wide. Total number of Facebook users worldwide1.2 Billion and the percentage of $18-24$ year olds who already use social media is $98 \%$. Total percentage of people on Earth who use Facebook regularly is $11 \%$. Average amount of time a person uses Facebook per month 15 hours 33 minutes and total amount of people who access Facebook with phone is 250 million. Percent of Facebook users under the age of 10 is $25 \%$. Total pieces of content shared on Facebook each month70 billion. Total amount of articles hosted by Wikipedia is 17 million.

Monthly active users now total nearly 850 million[13]. 21 percent of Facebook users are from Asia, which is only less than 4 percent of Asia's population. 488 million users regularly use Facebook mobile [14] 23 percent of Facebook's users check their account 5 or more times daily [15]. Facebook hosts 42 million "Pages" with 10 or more likes [16].80 percent of social media users prefer to connect with brands through Facebook [17].

Considering the situation describe above, we can easily understand the point that huge number of people are involving fully in social networking Facebook. But most of them are wasting their time in vain. If we can utilize their time by adapting education with social network, we will able to give our youth generation a strong and qualified life.

\section{Traditional education system}

In our teaching institute, the teacher gives lecture in so-called way. He comes into class with a few books, a marker pen and a duster. He starts to discuss about any topics according to syllabus and continue it to the end of class time. On that time a small part of students join that lecture and spread there thinking but a good number of students do not attend the lecture. Sometimes teacher asks some students a few questions. Then he gives assignment to the students on that topic and leaves the class. The next day he gets return the assignment from the students but do not check that does he or she does all the assignment along himself or herself, so the back-bench students remain poor always. After completing few classes the teacher gives exam but on that time he cannot able to judge them properly.

Only for so-called teaching system, maximum students cannot able to take proper education because of poor understanding. That's why they go drawn back and suffer in future. They complete courses but do not get proper education. For that reasons they are losing their confident level to do something in future life and so education level of the country fallen down continuously.

\section{Social education vs. traditional learning}

There are a huge number of differences between our traditional learning and social network based education. With the improvement of information technology people are going forward to reach the best destination. And that time social media help them to run faster than others. But in class room learning maximum students are blocked in a box and which creates a wall in front them. To cross the border and reach the destination students have to cope with new technologies, changing environments, and conflicting changes in capstone projects. They often lack practical experience, which might lead to failing to achieve a project's learning goals. In addition, the Net Generation students put new requirements upon software engineering education because they are digitally literate, always connected to the Internet and their social networks [9].

Results of prior distance learning studies are mixed. Some conclude that distance learning is at least as effective as traditional classroom learning, while others have found that graduate students in traditional face-toface courses outperformed those in web courses [10]. Not only that today's students grew up with Internet access, YouTube, Facebook, MySpace, and a host of other digital resources. They are trying to know outside world. But in class room they do not get those kinds of sufficient resources. For that cause the students are losing their interest to join the routine bound regular same style class.

In Bangladesh the scenario are like similar. The college and university students are fully driven in social networking sites basically Facebook. They waste huge time on it by visiting pages, chatting, sharing different things with others, giving comments on status, picture and so on. But sometimes they are not felling interest to join the regular class. They do not find the proper track of life, so as a result the lost their hope and ruin at last. So this crying needs to show them a smooth way through which they can find out the goal to lead their life properly. And it may possible to find out a new teaching method by mixing up social media and class room education.

In Bangladesh point there have some difference between traditional learning and social education and here they are

$\cdots$ 


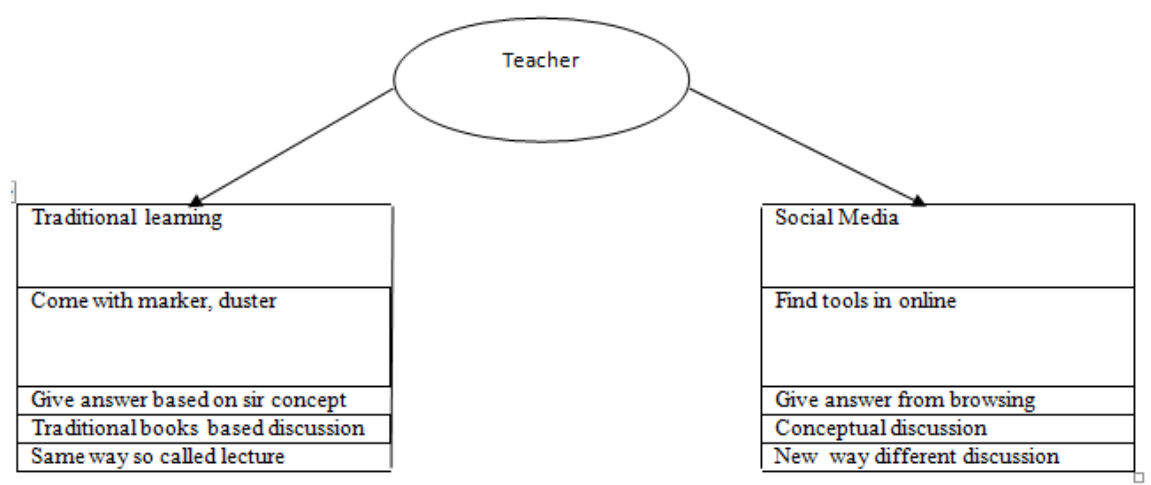

Figure2: Teacher involvement in social networks

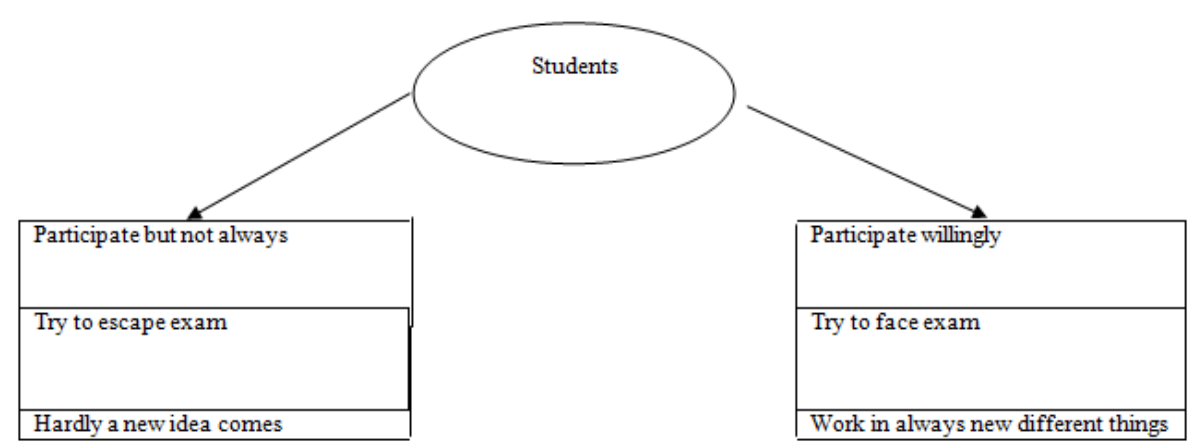

Figure3: Students involvement in social networks

VI.

Related Work

Since its creation in 2004, Facebook has become one of the most frequently visited websites on college campuses. Because of this rise in popularity, the subject of social networking has grown as an idea and concern for both faculty members and students. At Lee University, it has been observed that a growing number of faculty members have indeed created Facebook profiles. According to Pascarella and Terrenzini (1991), some of the most effective faculty members are those that create an informal relationship with their students. Over recent decades, numerous studies have suggested that student and faculty interaction has a notable impact on students "outcome, both in the intellectual and the social realm" (Endo \&Harpel; 1982). This study examines the opinions and reactions of faculty members and students at Lee University in Cleveland, TN in reference to their use of Facebook and how it affects ones education, directly or indirectly [11].

In some college and university, there have started flips class to modify the students in lifelong learning. The lecturer gives all the course materials like slides, references, link, and tools on social sites. Students have full freedom to choose his interested topics and study over that. After that the students make project or slide on it and in class they will make open discussion. Through this, the students become self-confident and the teacher make sure to notice all the students' activities [12].

\subsection{Social Networking \& Education:}

\section{CASE Study}

Technology can have a reciprocal relationship with teaching. At present social media has become a part of e-learning. In social network students pass many time without doing anything. The emergence of new technologies pushes educators to understanding and leveraging these technologies for classroom use. If the education system can be mixed up with the social media, the student may be benefited because there are many students who are more comfort in social site like Facebook. Through mixing both they may get education and fulfill the lacking about the studies. On-the-ground implementation of these technologies in the classroom can directly impact how these technologies continue to take shape.

$>$ Social network (Face-book):

Face-book is the most popular social sites to students. It provides huge application to them .like....

- Messaging - Send and receive messages;

- Groups - Create groups for the class or small group work and study;

- Links - Share interesting educational websites;

- Notes - Add small texts, reflections and observations that can be commented on; 
- Events - Create events such as assessments, proposal and delivery of papers, seminars and workshops, with the ability to add details (descriptions, images, videos and links), invite people, promote the event on an ad, edit and print the guest list and comment on the event;

- Photos - Allow you to load and take pictures or make an album;

- Video - Lets you record and upload a video;

- Chat - Real-time communication, great online service for students;

- Google Docs - Google Docs access through Facebook;

- Favorite Pages - Add favorite pages of the Facebook profile;

- Quiz Creator - application for creating tests;

- Polls - Application for surveys;

- Books iRead - application to share books (which we read, books read, or would like to read), add tags and comments from friends;

- Book Tag - Creates lists of books read in class, you can create quizzes and ideas in the form of commentaries on the books;

- Files - Allows you to store and retrieve documents on Facebook;

- Calendar - to organize your daily activities, putting up signs and share with friends; [5]

We can use all this application in our education sector by modifying them.

\subsection{Our Application (BASED ON FACE-BOOK)}

We want to make Facebook as a supported part of study; so that we can influence those students who do not able to find any new test and flavor form his education. He or she goes down from his bright future life. If we can get back their life we may get a healthy future of youth.[In figure 4 we show the way of solving any problem by involving all the students.]

In facebook(FB), there creates a group according to the course by the teacher and all the students must join the group. The course teacher gives information there about course materials, class topics, related topics etc. In the class room teacher take small time to give lecture. He gives different topics and related post, like link, document etc. in the group.

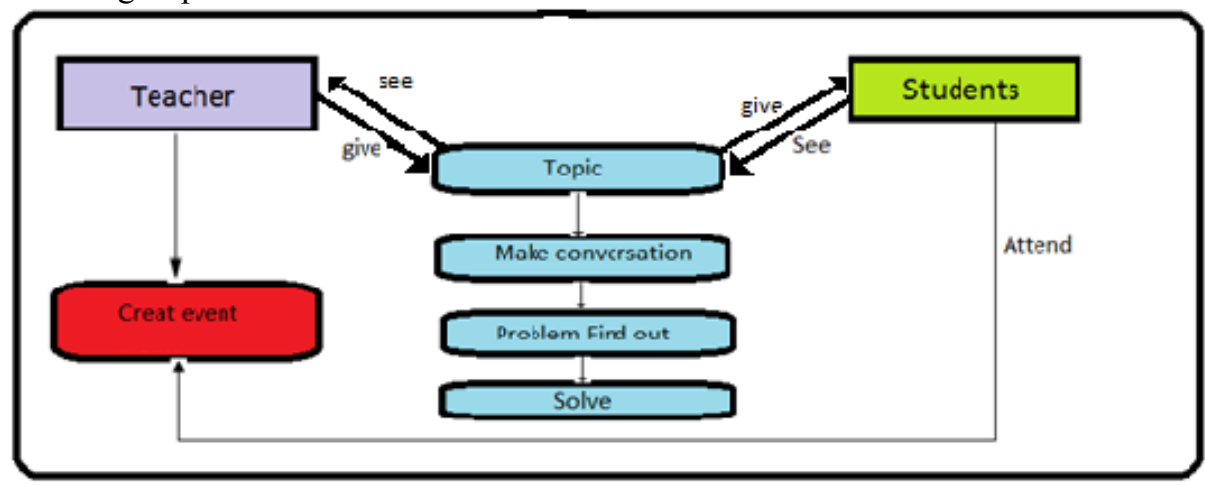

Figure4: Way of problem solving in Facebook group

The teacher gives a topic related to course in the group for discussion. All the students give comment on the comment box based on what they understand. They discuss about the topics at a time and search for more information. Than the students also post the information which they learn through searching.The teacher also shows the new topics posted by the students and he gives his opinion on it. Based on their comments and discussion, the next class teacher will discuss and solve that part which is not understandable through the students. 


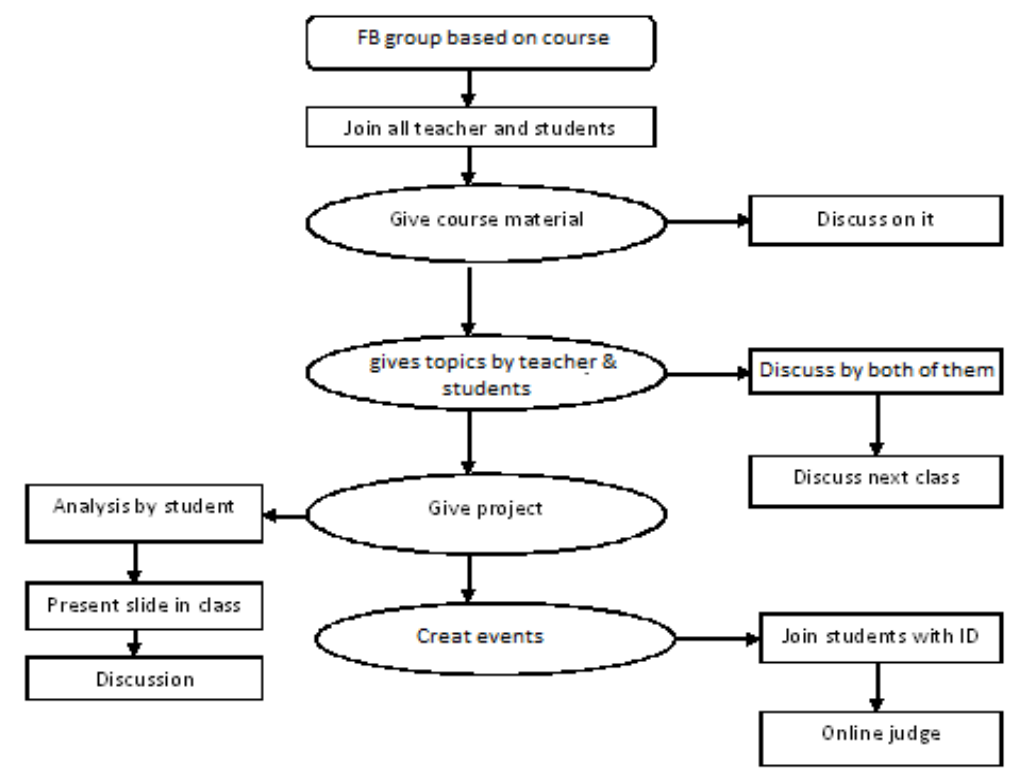

Figure 5: Flow chart diagram of FB learning

Than the teacher suggest the students to make a real life documentation or slide or project based on the topics and submit it on the group with his ID. For that all the students can see the work and influence themselves to do something new and innovative for his life. After that the next class the students will present the topics in front of the students and teacher. Through this work the teacher can find out whose student does the project along him and how much he confidents about his learning.

After that teacher may create an event to for students according to all the topics that are discussed and the students do some things with his own. Different peoples and teachers can also join the event. They show the work done by the students. Teacher may judge all the project or documentation and make a note according to the work. Than in the next class teacher make a presentation based on their work all the topics.

Through all this the teacher may able to find out those students who are not interested in so-called learning system. And he can motivate those students in real life learning involving them in new challenge. For these kinds of new work, all the students must be able to make them confident to do something and the education level is increased high by getting proper education to the students.

\subsection{User:}

There are two types of user in the system. They are Teacher and Students

\begin{tabular}{|l|l|}
\hline User & Definition \\
\hline Teacher & The person who will teach the students to make them literate and shine in future \\
\hline Students & Students are that's people who wants to get education and for that reasons trying hard \\
\hline
\end{tabular}

\section{User profile:}

\begin{tabular}{|l|l|l|}
\hline User class: Teacher & Note for characteristics & Requirement implied \\
\hline Type of user & Teacher & Must join in the group Crouse \\
\hline Education & Literate & \\
\hline Language Skills & Required & \\
\hline Computer Experience & Compulsory & Use Face-book. \\
\hline
\end{tabular}

\begin{tabular}{|l|l|l|}
\hline User class: Students & Note for characteristics & Requirement implied \\
\hline Type of user & Students & Must join in the group Crouse \\
\hline Education & Literate & \\
\hline Language Skills & Required & \\
\hline Computer Experience & Compulsory & Use Face-book. \\
\hline
\end{tabular}

VIII.

Benefits:

Through this system all the students get opportunity to improve their basic education. Because through this system all the student of a class must joinwith the support of open discussion different new ideas have 
opened. So, new ways of education create.Student can spread their mind outside of box and for that reasons they can able to do anything with his our confidence.Student will cope with the IT site and able to gather knowledge.

\section{Conclusion}

The science and technology going faster and if we want to cope with this, we have to improve our education for real life learning. So that, our young generation can builds up themselves as a strong identity. If we want to develop them perfectly, we must modify our education system. We may elevate our education system through social network as a strong supported part of education.

There are some lacking and obstacles of this system. In non-IT course they must use social media and the teacher must able to know proper use of it. But if we try, we may able to make it more flexible and comfort to use in our educational environment.After doing all this we may bring a new thought of education system for involving all the students on lifelong education to make their bright future.

\section{Reference:}

[1] NikleiaEteokleous and DespoKtoridou, "Facebook - A Social networking tool foreducational purpose: developing specialinterest groups Frederick University, IacovosStavridesand MichalakisMichaelidisUniversity of Nicosia Cypru.

[2] Waqas Tariq, MadihaMehboob, M. Asfandyar Khan and FaseeUllah, "The Impact of Social Media and Social Networks on Education and Students of Pakistan" 1 Department of Computer Science,City University of Science \& Information Technology,Peshawar - Pakistan, 2 Department of Management SciencesCity University of Science \& Information Technology,Peshawar - Pakistan, 3 Department of Science \& Technology UnitUMM AL QURA University, Makkah, Saudi Arabia

[3] Shona Leitch and Matthew J. Warre, "Social Networking and Teaching: An Australian Case Study",School of Information Systems, Faculty of Business and Law, Deakin University, Burwood, Victoria, Australia

[4] Ashraf Jalal YouseofZaidieh, "The Use of Social Networking in Education: Challenges and Opportunities" ICT, collage of information and communication technology, IIUM KL, Malaysia

[6] Rhona Sharpe and Greg Benfield, "The Student Experience of E-learning in Higher Education: A Review of the Literature"

[7] Sarah Knight Program Manager, "Effective Practice with e-Learning, e-Learning and Pedagogy" JISC Development Group University of Bristol.

[8] Boyd, D. M., \& Ellison, N. B. (2008). Social network sites: Definition, history, and scholarship. Journal of Computer-Mediated Communication, 13, 210-230.

[9] Ras, E., \&Rech, J. (2009)."Using Wikis to support the Net Generation in improving knowledge acquisition in capstone projects."The Journal of Systems and Software, 82 (4), 553.

[10] C. Chen, Keith T. Jones, "Blended Learning vs. Traditional Classroom Settings: Assessing Effectiveness and Student Perceptions in an MBA Accounting CourseClement", University of Michigan - Flint, Illinois State University.

[11] Sturgeon, C. M, \& Walker, C. (2009)."Faculty on Facebook: Confirm or Deny?"Paper presented at the Annual Instructional Technology Conference, Lee University, Cleveland, TN.

[12] Jeremy F. Strayer, B.S., M.A.Ed. "The Effects Of The Classroom Flip On The LearningEnvironment: A Comparison OfLearning Activity In A Traditional Classroom And AFlip Classroom That Used An Intelligent Tutoring SystemDissertation", Presented in Partial Fulfillment of the Requirements forthe Degree Doctor of Philosophy in the GraduateSchool of The Ohio State University.

[13] http://www.jeffbullas.com/2012/04/23/

[14] http://allfacebook.com/socialbakers-mobile-infographic b88216

[15] http://www.socialnomics.net/2012/06/06/10-new-2012-social-media-stats-wow/

[16] http://www.jeffbullas.com/2012/04/30/20

[17] http://www.business2community.com/facebook/facebook-marketing-statistics-you-need-to-know-0289953 